\title{
A Phase Ib Study of the Dual PI3K/mTOR Inhibitor Dactolisib (BEZ235) Combined with Everolimus in Patients with Advanced Solid Malignancies
}

\author{
Trisha M. Wise-Draper ${ }^{1} \cdot$ Ganesh Moorthy $^{2} \cdot$ Mohamad A. Salkeni $^{1,3}$. \\ Nagla Abdel Karim ${ }^{1}$ - Hala Elnakat Thomas ${ }^{1}$ - Carol A. Mercer $^{1}$ - M. Shalaan Beg ${ }^{1,4}$. \\ Sue O'Gara $^{1}$ • Olugbenga Olowokure ${ }^{1}$ - Hassana Fathallah ${ }^{1}$ - Sara C. Kozma ${ }^{1,5}$. \\ George Thomas $^{1,5} \cdot$ Olivier Rixe $^{1,6}$ - Pankaj Desai ${ }^{2,7} \cdot$ John C. Morris ${ }^{1,8}$
}

Published online: 29 March 2017

(C) The Author(s) 2017. This article is published with open access at Springerlink.com

\begin{abstract}
Background The combination of everolimus and the imidazoquinoline derivative, BEZ235 (dactolisib), a dual $\mathrm{PI} 3 \mathrm{~K} / \mathrm{mTOR}$ inhibitor, demonstrated synergy in a preclinical model.

Objective To establish clinical feasibility, a phase Ib doseescalation trial investigating safety and pharmacokinetics of this combination in patients with advanced tumors was performed.

Patients and Methods BEZ235 was orally administered daily in escalating doses of 200, 400, and $800 \mathrm{mg}$ along with everolimus at $2.5 \mathrm{mg}$ daily in 28-day cycles. Nineteen patients were enrolled. Adverse events and tumor responses were evaluated using CTCAE v4.0 and RECIST 1.1, respectively. Pharmacokinetic analyses were performed.
\end{abstract}

Trisha M. Wise-Draper and Ganesh Moorthy are co-first authors

Electronic supplementary material The online version of this article (doi:10.1007/s11523-017-0482-9) contains supplementary material, which is available to authorized users.

Pankaj Desai

pankaj.desai@uc.edu

John C. Morris

morri2j7@ucmail.uc.edu

1 Division of Hematology-Oncology, Department of Internal Medicine, University of Cincinnati, Cincinnati, OH 45267, USA

2 Division of Pharmaceutical Sciences, University of Cincinnati, Cincinnati, OH 45267, USA

3 Division of Hematology-Oncology, Department of Medicine, West Virginia University Cancer Institute, Morgantown, WV 26506, USA

4 Division of Hematology-Oncology, University of Texas Southwestern, Dallas, TX 75390, USA
Results Common toxicities observed included fatigue, diarrhea, nausea, mucositis, and elevated liver enzymes. No confirmed responses were observed. BEZ235 pharmacokinetics exhibited dose-proportional increases in $\mathrm{C}_{\max }$ and $\mathrm{AUC}_{0-24}$ over the three doses, with high inter-individual variability. Non-compartmental and population pharmacokinetic-based simulations indicated significant increases in everolimus $\mathrm{C}_{\max }$ and $\mathrm{AUC}_{0-24}$ on day 28 and decreased clearance to $13.41 \mathrm{~L} / \mathrm{hr}$.

Conclusions The combination of BEZ235 and everolimus demonstrated limited efficacy and tolerance. BEZ235 systemic exposure increased in a dose-proportional manner while oral bioavailability was quite low, which may be related to gastrointestinal-specific toxicity. The changes in steady-state pharmacokinetics of everolimus with BEZ235 highlight po-

5 Institut Català d'Oncologia i Institut d'Investigació Biomèdica de Bellvitge, Laboratory of Cancer Metabolism, Hospital Duran i Reynals, 08908 Barcelona, Spain

6 Division of Hematology-Oncology, Department of Internal Medicine, University of New Mexico, Albuquerque, NM 87106, USA

7 The James L. Winkle College of Pharmacy, University of Cincinnati, 3225 Eden Avenue, Cincinnati, OH 45267-0004, USA

8 Division of Hematology-Oncology, University of Cincinnati, Vontz Center for Molecular Studies, 3125 Eden Avenue, ML 0562, Cincinnati, OH 45267-0562, USA 
tential drug-drug interactions when these two drugs are administered together.

Clinicaltrials.gov: NCT01508104

\section{Key Points}

BEZ235 in combination with everolimus demonstrated superior survival in a preclinical model but limited clinical efficacy.

BEZ235 in combination with everolimus was poorly tolerated at administered doses in this phase I study.

BEZ235 resulted in increases in everolimus steady state pharmacokinetics when administered together.

\section{Introduction}

The development of molecularly targeted agents (MTA), small molecules or antibodies directed against specific oncogenic targets has transformed cancer therapy, leading to improved disease control and extended survival. However, only a few MTAs, such as imatinib have been successful as single agents, likely because many tumors develop alternate signaling pathways or harbor additional genetic alterations, and, hence, are not driven by a single mutation [1]. Therefore, heterogeneous tumors presumably require inhibition of multiple key signaling regulators, warranting combination therapy. The phosphatidylinositol 3-kinase/AKT/mammalian target of rapamycin (PI3K/AKT/mTOR) pathway has emerged as a central pathway in cell survival, proliferation, and angiogenesis that is frequently dysregulated in cancer and its activation has been associated with poor outcomes [2]. The mTOR inhibitor, everolimus (RAD001), is FDA-approved for the treatment of renal cell carcinoma, subependymal giant cell astrocytoma, pancreatic neuroendocrine tumors, and advanced breast cancer [3-5]. However, obtaining optimal clinical responses with single-agent everolimus is challenging, perhaps due to loss of a negative feedback mechanism that results in activation of PI3K and its downstream effectors, or due to incomplete inhibition of mTORC1 substrates such as 4EBP1 [6, 7]. BEZ235 is a dual PI3K/mTOR inhibitor that binds to the ATP-binding pocket of these enzymes, thereby inhibiting PI3K along with mTOR complexes, TORC1, and TORC2 [8]. Preclinical studies in mouse transgenic and xenograft tumor models have shown that BEZ235 effectively inhibits growth of tumors, including glioblastoma, breast, lung, pancreatic, and prostate cancer [9-12].

We previously reported that the combination of BEZ235 and everolimus slowed progression of hepatocellular carcinoma (HCC) in mice [13]. Microarray gene expression analyses revealed that a number of genes in tumors treated with the drug combination, but not as single agents, reverted to expression levels found in normal liver. Furthermore, the expression of autophagy genes was decreased in tumors compared to normal liver [13]. These findings formed the basis for this phase I study to evaluate the safety and efficacy of this combination in patients with advanced cancer.

Everolimus is primarily metabolized by CYP3A4 $[14,15]$ and is also a substrate for efflux transporter P-glycoprotein (Pgp) [16]. A number of clinical trials investigating drug-drug interactions have established everolimus to be a sensitive probe for alterations in CYP3A4/ P-gp activity [17]. Therefore, we chose a starting dose of $2.5 \mathrm{mg}$ of everolimus (rather than standard dosing of $10 \mathrm{mg}$ ) to account for this interaction. We report a detailed description of the combination pharmacokinetics (PK) of BEZ235 and its potential impact on everolimus.

\section{Methods}

\subsection{Eligibility Criteria}

For this IRB-approved study, BEZ235 was supplied by Novartis Oncology (East Hanover, NJ, USA). Patients $\geq 18$ years with cytologically or histologically confirmed advanced or metastatic solid cancers that had exhausted standard therapies were eligible for enrollment. At least one measurable lesion defined by RECIST 1.1 was required [18]. Key inclusion criteria were Eastern Cooperative Oncology Group performance status (ECOG PS) $\leq 2$, ability to understand and sign informed consent, and adequate bone marrow and organ function [19]. Key exclusion criteria included prior anticancer therapy within 4 weeks prior to enrollment, poorly controlled diabetes, chronic immunosuppression, other serious disease that may impact survival, abnormal gastrointestinal function resulting in poor BEZ235 absorption, or required treatment with other drugs that are known to modulate isoenzyme CYP3A4.

\subsection{Study Design and Dose Escalation Scheme}

The study was an open-label, single-center, dose-escalation trial assessing the safety and tolerability of the combination of BEZ235 and everolimus (NCT01508104). The primary objectives of the study were to determine the maximum tolerated dose (MTD) and dose-limiting toxicities (DLT) in patients with solid tumors. The secondary objective was to characterize the PK of BEZ235 and everolimus in combination. Nineteen patients were enrolled from $1 / 12 / 12$ to $9 / 30 / 13$ (Table 1). Patients were treated in 28-day cycles that included once daily oral administration of everolimus and BEZ235. 
Table 1 Patient demographics

\begin{tabular}{|c|c|c|c|c|}
\hline $\begin{array}{l}\text { Demographic or patient } \\
\text { characteristic }\end{array}$ & $\begin{array}{l}\text { BEZ235 } 200 \mathrm{mg} / \\
\mathrm{d}+2.5 \mathrm{mg} / \mathrm{d} \\
\text { Everolimus } \\
(\mathrm{N}=4)\end{array}$ & $\begin{array}{l}\text { BEZ235 } 400 \mathrm{mg} / \\
\mathrm{d}+2.5 \mathrm{mg} / \mathrm{d} \\
\text { Everolimus } \\
(\mathrm{N}=7)\end{array}$ & $\begin{array}{l}\text { BEZ235 } 800 \mathrm{mg} / \\
\mathrm{d}+2.5 \mathrm{mg} / \mathrm{d} \\
\text { Everolimus } \\
(\mathrm{N}=8)\end{array}$ & $\begin{array}{l}\text { Total } \\
(\mathrm{N}=19)\end{array}$ \\
\hline Age (median, years) & $\begin{array}{l}59 \\
\text { (range 36-64) }\end{array}$ & $\begin{array}{l}57 \\
\text { (range 54-73) }\end{array}$ & $\begin{array}{l}52 \\
\text { (range 38-62) }\end{array}$ & 56 \\
\hline Male & 3 & 3 & 6 & 12 \\
\hline Female & 1 & 4 & 2 & 7 \\
\hline ECOG PS $=0$ & 0 & 2 & 1 & 3 \\
\hline ECOG PS = 1 & 4 & 5 & 6 & 15 \\
\hline ECOG PS $=2$ & 0 & 0 & 1 & 1 \\
\hline White & 3 & 6 & 6 & 15 \\
\hline Black & 1 & 1 & 1 & 3 \\
\hline Hispanic & 0 & 0 & 1 & 1 \\
\hline \# Prior treatments & $\begin{array}{l}3.5 \\
\text { (range 2-5) }\end{array}$ & $\begin{array}{l}3 \\
\text { (range 2-9) }\end{array}$ & $\begin{array}{l}3.5 \\
\text { (range 1-5) }\end{array}$ & $\begin{array}{l}3 \\
\text { (range 1-9) }\end{array}$ \\
\hline Days of treatment received & $\begin{array}{l}56 \\
\text { (range 18-56) }\end{array}$ & $\begin{array}{l}19 \\
\text { (range 6-56) }\end{array}$ & $\begin{array}{l}15 \\
\text { (range 5-46) }\end{array}$ & $\begin{array}{l}24 \\
\text { (range 5-56) }\end{array}$ \\
\hline \multicolumn{5}{|l|}{ Tumor types } \\
\hline NSCLC & 1 & 1 & 0 & 2 \\
\hline Brain tumor & 1 & 1 & 1 & 3 \\
\hline Colon carcinoma & 1 & 1 & 1 & 3 \\
\hline $\mathrm{HCC}$ & 1 & 0 & 0 & 1 \\
\hline Pancreatic $\mathrm{Ca}$ & 0 & 1 & 0 & 1 \\
\hline Esophageal Ca & 0 & 1 & 1 & 2 \\
\hline $\begin{array}{l}\text { Laryngeal ca } \\
\text { (adenoid cystic) }\end{array}$ & 0 & 1 & 0 & 1 \\
\hline Appendix ca & 0 & 1 & 0 & 1 \\
\hline HNSCC & 0 & 0 & 1 & 1 \\
\hline Prostate ca & 0 & 0 & 1 & 1 \\
\hline Ovarian ca & 0 & 0 & 1 & 1 \\
\hline Rectal NET & 0 & 0 & 1 & 1 \\
\hline Endometrial $\mathrm{Ca}$ & 0 & 0 & 1 & 1 \\
\hline
\end{tabular}

The starting dose of everolimus was $2.5 \mathrm{mg}$ and $200 \mathrm{mg}$ for BEZ235. BEZ235 was escalated to $400 \mathrm{mg}$ and $800 \mathrm{mg}$ in cohorts 2 and 3, respectively. Patients self-administered and reported daily everolimus and BEZ235 dosing on a patient calendar. Patients were treated until either unacceptable toxicity was reached or until disease progression.

Safety was evaluated by monitoring adverse events, hematology, blood chemistry profiles, and regular physical exams. Adverse events were graded using CTCAE v4.1. Dose reductions and delays were allowed for significant drug-associated toxicities of up to 2 weeks. At least three patients were enrolled in each cohort and dose escalation was permitted once three patients were evaluable for DLT. At each given dose level, there was a gap of 1 week between the inclusion of the first patient and the next two patients. Assessment for DLT was conducted during the first 28 days after enrollment. The DLT was defined as febrile or grade 4 neutropenia
$>7$ days, grade 4 thrombocytopenia or grade 3 with bleeding, grade 3 or 4 non-hematologic toxicity, treatment delay $\geq 2$ weeks due to unresolved toxicity, or any other nonhematologic toxicity grade 2 or higher that the investigator and medical monitor felt was dose-limiting. If a patient developed a DLT, then three more patients were entered at that dose level. The MTD was the dose in which $\leq 1$ patient developed a DLT.

\subsection{Patient Evaluation}

After informed consent, baseline visit included general demography, medical history including medications, thorough physical exam, vital signs, ECOG PS, ECG, blood collection for standard laboratory investigation, cardiac and CT wholebody imaging, brain MRI (for brain tumors), and pulmonary function testing. Tumor response was measured using 
RECIST criteria every 8 weeks. After discontinuation of study medication, an end of study visit was performed at 30 days.

\subsection{Pharmacokinetic Assessment and Determination of Everolimus and BEZ235 Concentrations}

Blood samples for PK analysis of BEZ235 and everolimus were obtained pre-dose and at 1, 2, 4, 6, 8, 10, and $24 \mathrm{~h}$ after dosing on days 1 and 28. Additional blood samples were collected at 48 and $72 \mathrm{~h}$ after the last dose (day 28). For BEZ235 PK, blood was collected into sodium heparin tubes and the plasma was separated. For everolimus PK, blood was collected into ethylenediaminetetraacetic acid (EDTA)-containing tubes and stored at $-20{ }^{\circ} \mathrm{C}$ until analysis. Whole blood was preferred for everolimus analysis as it is extensively distributed into erythrocytes with binding of $85 \%$. BEZ235 concentrations were determined using fluorescence-based highperformance liquid chromatography (HPLC) method using BBD130 as an internal standard [20]. Everolimus concentrations were measured using a validated liquid chromatography coupled with mass spectrometer (LC-MS/MS) method (Supplementary Methods).

\subsection{Pharmacokinetic and Statistical Analysis}

Non-compartmental analysis using Phoenix WinNonlin 6.3 (Pharsight, Mountain View, CA, USA) was performed to determine $\mathrm{PK}$ parameters including area under the plasma concentration-time curve from zero to last measurable time point $\left(\mathrm{AUC}_{0-24}\right)$, maximum plasma concentration $\left(\mathrm{C}_{\max }\right)$, time to achieve the peak concentrations $\left(\mathrm{T}_{\max }\right)$, terminal elimination half-life $\left(\mathrm{t}_{1 / 2}\right)$, and oral clearance $(\mathrm{CL} / \mathrm{F})$. The elimination half-life $\left(\mathrm{t}_{1 / 2}\right)$ was calculated as $0.693 / \lambda_{\mathrm{z}}$, where $\lambda_{\mathrm{z}}$ is the terminal-phase elimination rate constant. $\mathrm{AUC}_{0-24}$ was calculated using the linear trapezoidal rule area under the concentration time curve from time zero to 24 hours. Dose proportionality was assessed using the power model $\mathrm{Y}=\alpha(\text { dose })^{\beta}$, where $\mathrm{Y}$ is the response variable $\left(\mathrm{C}_{\max }\right.$ and $\left.\mathrm{AUC}_{0-24}\right), \alpha$ is the expected value of $Y$ at a reference dose, and $\beta$ is the exponent used for examining the proportionality. In order to evaluate the postulated impact of BEZ235 on everolimus PK, the singledose and steady-state systemic exposure of everolimus $\left(\mathrm{C}_{\max }\right.$ and $\left.\mathrm{AUC}_{0-24}\right)$ and $\mathrm{CL} / \mathrm{F}$ derived from our study were compared to those previously reported. Statistical analysis (Wilcoxon signed rank test, at 0.05 significance) was performed to test if there was a significant change in primary PK parameters of everolimus from day 1 to day 28. We also employed a population PK model using NONMEM 7.2 (Icon Development Solutions, MD, USA) which facilitates nonlinear fixed-effect modeling to further strengthen this comparison.

\section{Results}

\subsection{Patient Characteristics}

Thirty-four patients were screened and 19 patients were eligible for enrollment (Fig. 1). All had advanced solid tumors and had failed conventional therapy (Table 1). About half of the patients were male and the median age was 56 years (range, 36-73 years). The majority of patients had an ECOG PS of 1. On average, patients had received at least three prior systemic treatments.

\subsection{Dose Escalation, Safety and Maximum Tolerated Dose}

The study was initially designed to include five cohorts, but due to early termination included only three (Supplementary Table 1). The study was closed early due to exceeding the MTD in cohort 3. All 19 patients reported at least one adverse event. Four patients developed a DLT requiring discontinuation of the study drug and one patient died. Several patients reported malaise during the first several days of medication and discontinued treatment despite symptom resolution but did not fulfill criteria for DLT determination. Four additional patients withdrew consent, one patient was removed for noncompliance, and one had a prolonged delay in treatment due to toxicity requiring discontinuation (Fig. 1). Overall, there were 196 adverse and 34 serious adverse events reported, of which 9 were unrelated to study medication (Table 2). The most common adverse events included fatigue, anorexia, nausea, diarrhea, and mucositis (Supplementary Table 2). On laboratory evaluation, elevated liver enzymes and anemia were the most commonly recorded events.

In cohort 1 , in which patients received $200 \mathrm{mg}$ of BEZ235 and $2.5 \mathrm{mg}$ everolimus, there were three serious adverse events, but only one with elevation in liver enzymes was deemed to be study drug-related. Non-related serious adverse events included hydrocephalus in a patient with glioblastoma multiforme (GBM) and pneumonia requiring hospitalization. Otherwise, the first cohort of patients tolerated the treatment well and all but one patient completed two full cycles. In cohort 2 , the dose of BEZ235 was escalated to $400 \mathrm{mg}$ while everolimus dose remained the same. A total of seven patients were treated in this cohort as one DLT was observed. There were 14 serious adverse events with the majority encompassing laboratory abnormalities including elevated liver enzymes and anemia. The DLT observed was due to angioedema and its relationship to the study drug could not be excluded. In this cohort, several patients developed nausea and diarrhea as well as mucositis. As mucositis is a known side-effect of everolimus [21], the increased rates of mucositis with two mTOR inhibitors was not unexpected. One case of diarrhea and one case of mucositis were related to infectious causes: Clostridium difficile and herpes simplex virus, respectively. Cohort 3 included 8 patients treated with 
Fig. 1 Consort diagram. The schematic demonstrates patient enrollment and allocation
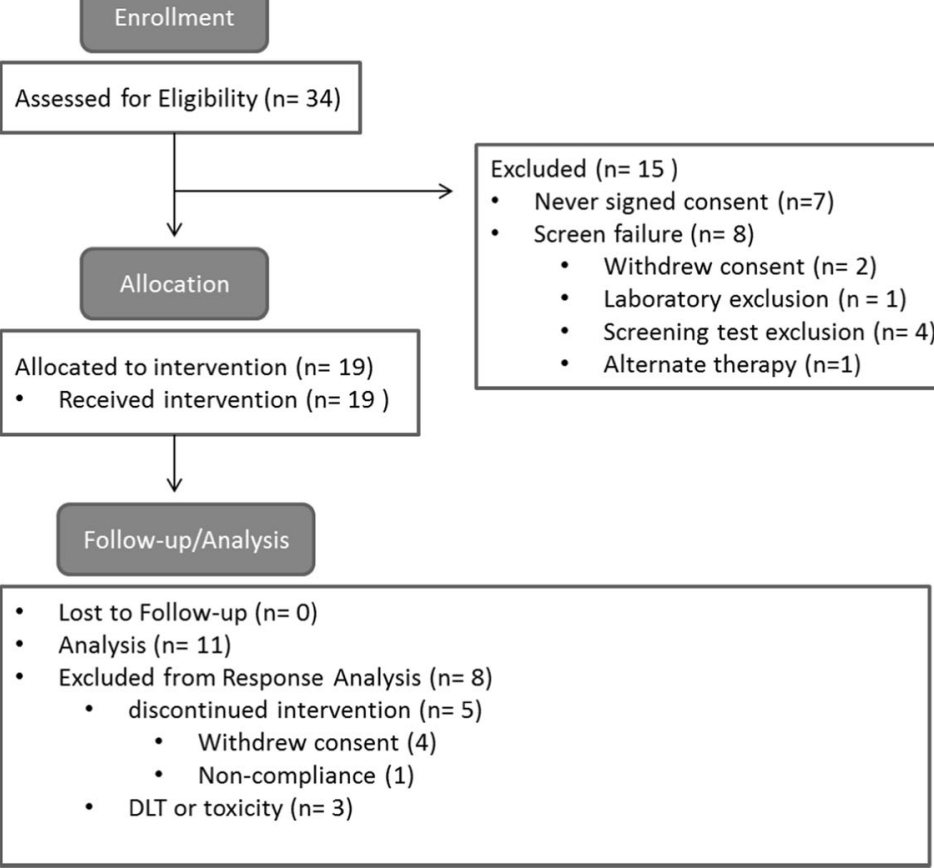

BEZ235 at $800 \mathrm{mg}$ with $2.5 \mathrm{mg}$ everolimus. Most patients in cohort 3 developed fatigue, mucositis, diarrhea and nausea and several patients required treatment delays or dose reduction due to drug toxicity with 17 serious adverse events. Of the grade 3/4
Table 2 Serious adverse events (CTCAE grade 3-5)

\begin{tabular}{|c|c|c|c|c|}
\hline Toxicity category & Toxicity & Cohort 1 & Cohort 2 & Cohort 3 \\
\hline \multirow[t]{3}{*}{ General symptoms } & Fatigue & & $1(14)$ & $1(13)$ \\
\hline & Angioedema & & $1(14)$ & \\
\hline & Dehydration & & $2(28)$ & \\
\hline \multirow[t]{9}{*}{ Lab abnormalities } & ALT Elevation & & & $1(13)$ \\
\hline & AST Elevation & $1(25)$ & $1^{+}(14)$ & $2(25)$ \\
\hline & Alkaline phosphatase elevation & & $2^{+}(28)$ & $1(13)$ \\
\hline & Elevated bilirubin & & $1^{+}(14)$ & \\
\hline & Tumor lysis syndrome & & & $1^{*}(13)$ \\
\hline & Hypophosphatemia & & & $1(13)$ \\
\hline & Anemia & & $2(28)$ & $1(13)$ \\
\hline & Neutropenia & & $1^{*}(14)$ & \\
\hline & Thrombocytopenia & & & $1(13)$ \\
\hline \multirow[t]{4}{*}{ Gastrointestinal symptoms } & Mucositis & & $1(14)$ & $1(13)$ \\
\hline & Diarrhea & & $1(14)$ & $1(13)$ \\
\hline & Nausea/vomiting & & & $1(13)$ \\
\hline & Hepatorenal syndrome & & & $1^{*}(13)$ \\
\hline \multirow[t]{3}{*}{ Infectious complications } & Gram positive bacteremia & & & $2^{+* * *}(25)$ \\
\hline & Pneumonia $^{+}$ & $1(25)$ & & \\
\hline & Perforated diverticulitis ${ }^{+}$ & & & $1^{*}(13)$ \\
\hline \multirow[t]{3}{*}{ Neurologic symptoms } & Gait imbalance $^{+}$ & & $1(14)$ & \\
\hline & Hydrocephalus $^{+}$ & $1^{*}(25)$ & & \\
\hline & Peripheral neuropathy & & & $1(13)$ \\
\hline
\end{tabular}

${ }^{+}$Due to disease progression rather than study medication. *Grade 4 events included neutropenia, tumor lysis syndrome, hepatorenal syndrome, gram positive sepsis, diverticulitis, and hydrocephalus. **Grade 5 event included an episode of gram positive sepsis. The percentage of adverse events in each cohort is indicated in (). 
events, one patient developed diverticulitis and perforation resulting in sepsis unrelated to treatment, while another developed tumor lysis syndrome (TLS) after only 5 days of treatment with elevation in lactate dehydrogenase (LDH) and uric acid, hepatorenal failure and gram-positive bacteremia which was potentially related to treatment. The latter patient succumbed to the adverse events and was recorded as a DLT. Two other DLTs were observed: one due to a grade 3 peripheral neuropathy, and on retrospective review of laboratory findings, it was determined that a previous patient had experienced a DLT due to grade 3 hypophosphatemia. Therefore, it was determined that MTD had been reached in the previous cohort $(400 \mathrm{mg}$ of BEZ235 and $2.5 \mathrm{mg}$ of everolimus).

Only four patients $(21 \%)$ completed two full cycles of treatment and no patients began a third cycle, as all that were evaluable at the end of cycle 2 had disease progression. The most common reason for early termination was due to withdrawal of consent, toxicity leading to prolonged delay, or a DLT.

\subsection{Tumor Response}

Eleven patients were evaluable for response. One patient with astrocytoma had stable disease and no responses were observed (Supplementary Table 3). Although treatment was tolerated well in cohort 1 , all patients in both cohort 1 and 2 developed disease progression requiring study discontinuation. One patient with a rectal neuroendocrine tumor in cohort 3 had a transient clinical response at fifteen days; however, he developed grade 3 laboratory abnormalities requiring treatment delay during which he rapidly progressed and re-initiation of medication was unsuccessful. Although, there was one confirmed stable disease (SD) and one patient who had an observed initial clinical response as described above, the study was discontinued after cohort 3 due to intolerable adverse effects.

\subsection{Pharmacokinetics of BEZ235}

Plasma concentration-time profile data of BEZ235 at 200, 400, and $800 \mathrm{mg}$ on day 1 are shown in Fig. 2a, and the noncompartmental PK parameters are listed in Table 3. The peak plasma concentration of BEZ235 occurred approximately 3 hours after administration and the median $\mathrm{T}_{\max }$ values were $3.8 \pm 1.6,2.5 \pm 0.9$, and $2.6 \pm 0.8$ hours at doses of 200,400 , and $800 \mathrm{mg}$, respectively. There was a significant interindividual variability in BEZ235 $\mathrm{PK}$. The plasma concentration maximum $\mathrm{C}_{\max }$ (mean $\pm \mathrm{SE}$ ) increased in a dose-proportional manner from $45.2 \pm 11.4,101.8 \pm 22.4$ and $243.0 \pm 52.7 \mathrm{ng} / \mathrm{mL}$ and the corresponding dose normalized $\mathrm{C}_{\max }$ was $0.2,0.3$, and 0.3 at 200, 400, and $800 \mathrm{mg}$ BEZ235 doses, respectively. The $\mathrm{AUC}_{0-24}$ (mean $\pm \mathrm{SE}$ ) values were $433.4 \pm 96,741.3 \pm 171.2$, and $2081.5 \pm 666.2 \mathrm{hr} * \mathrm{ng} / \mathrm{mL}$ for 200,400 , and $800 \mathrm{mg}$ BEZ235 doses, respectively. The elimination half-life showed higher variability across dose groups with mean values of
3.2 hours at $200-\mathrm{mg}, 8.6$ hours at $400-\mathrm{mg}$, and 5.9 hours at $800-\mathrm{mg}$ doses. Dose proportionality in BEZ235 PK was established by linear regression analysis and also by a power model for systemic exposure parameters $\mathrm{C}_{\max }$ and $\mathrm{AUC}_{0-24}$ with BEZ235 dose. The $\beta$-slope parameter for power model for $\mathrm{C}_{\max }$ and $\mathrm{AUC}_{0-24}$ were 1.21 and 1.13 , respectively. Further, the linear regression of $\mathrm{C}_{\max }$ and $\mathrm{AUC}_{0-24}$ to BEZ235 dose was linear with $\mathrm{R}^{2}$ of 0.9973 with $P=0.0127$ (for slope $\neq 0$ ) for $\mathrm{C}_{\max }$ and $\mathrm{R}^{2}$ of 0.9833 with $P=0.013$ (for slope $\neq 0$ ) for $\mathrm{AUC}_{0-24}$ (Supplementary Figure 1). Steady-state PK parameters of BEZ235 are listed in Table 3. There was a significant accumulation of BEZ235 on day 28 as indicated by $\mathrm{C}_{\max }$ and $\mathrm{AUC}_{0-24}$; steady-state terminal half-life was estimated to be $19.2 \pm 2.5,43.4 \pm 10.8$, and $15 \pm 6.4$ hours at doses of 200,400 , and $800 \mathrm{mg}$, respectively.

\subsection{Everolimus Pharmacokinetics and Drug Interactions}

Everolimus whole-blood concentration-time profile data at $2.5 \mathrm{mg} /$ day is shown in Fig. $2 \mathrm{~b}$ and PK parameters are listed in Table 3. The $C_{\max }$ on day 1 was $14.08 \pm 1.5 \mathrm{ng} / \mathrm{mL}$ and was observed at a $\mathrm{T}_{\max }$ of $4.3 \pm 1.2$ hours. The apparent clearance $(\mathrm{CL} / \mathrm{F})$ was $24.76 \pm 2.91 \mathrm{~L} / \mathrm{hr}$, which was close to the reported everolimus clearance of $21.3 \mathrm{~L} / \mathrm{hr}$ and $27.3 \mathrm{~L} / \mathrm{hr}$ at 5 and $10 \mathrm{mg}$ dosed alone [22]. To investigate any impact of BEZ235 co-administration on everolimus PK, dosenormalized $\mathrm{AUC}_{0-24}$ and $\mathrm{C}_{\max }$ observed on days 1 and 28 were compared with the reported values at 5 and $10 \mathrm{mg} /$ day. The $\mathrm{AUC}_{0-24}$ was $124.32 \pm 12.7 \mathrm{ng} * \mathrm{hr} / \mathrm{mL}$ on day 1 and increased to $218.8 \pm 33.26 \mathrm{ng} * \mathrm{hr} / \mathrm{mL}$ on day 28 . Similarly, $\mathrm{C}_{\max }$ increased from $14.08 \pm 1.5 \mathrm{ng} / \mathrm{mL}$ on day 1 to $31.68 \pm 7.4 \mathrm{ng} /$ $\mathrm{mL}$ on day 28 . In contrast, clearance of everolimus (CL/F) decreased from $24.76 \pm 2.91 \mathrm{~L} / \mathrm{h}$ on day 1 to $13.41 \pm 2.31 \mathrm{~L} /$ $\mathrm{hr}$ on day 28. Dose-normalized exposure and clearance values in this study were compared with everolimus PK from cancer patients as reported in the Afinitor ${ }^{\circledR}$ clinical pharmacology and biopharmaceutics review [23]. As shown in Fig. 3, there was a significant increase in everolimus systemic exposure $\left(\mathrm{C}_{\max }\right.$ and $\left.\mathrm{AUC}_{0-24}\right)$ and corresponding decrease in everolimus clearance $(\mathrm{CL} / \mathrm{F})$ on day 28 . Dose-normalized $\mathrm{C}_{\max }$ of everolimus was $9.29 \mathrm{ng} / \mathrm{mL}$ when given along with BEZ235 compared to $6.3 \mathrm{ng} / \mathrm{mL}$ when dosed alone. Similarly, there was a 1.7-fold increase in dose-normalized $\mathrm{AUC}_{0-24}$ with the combination of everolimus and BEZ235 when compared to everolimus alone. Further, there was a statistically significant decrease in clearance $(P$ value $=0.0156)$ from day 1 to day 28 . Since there were only a few subjects in each BEZ235 dose group, statistical analysis on the influence of BEZ235 dose on everolimus exposure was not performed. Figure 3a shows individual line plots of change in $\mathrm{CL} / \mathrm{F}$ and $\mathrm{AUC}$ in different subjects from day 1 to day 28 , further illustrating the potential drug-drug interaction, strongly suggesting a BEZ235 influence on everolimus PK. 
Fig. 2 Plasma concentrationtime profiles of BEZ235 and everolimus. a) Plasma concentration-time profile of BEZ235 on day 1 after 200,400 , and $800 \mathrm{mg}$ /day dose. b) Plasma concentration-time profile of everolimus on day 1 and day 28 after $2.5 \mathrm{mg} /$ day dose
Observed Concentration vs Time after Dose

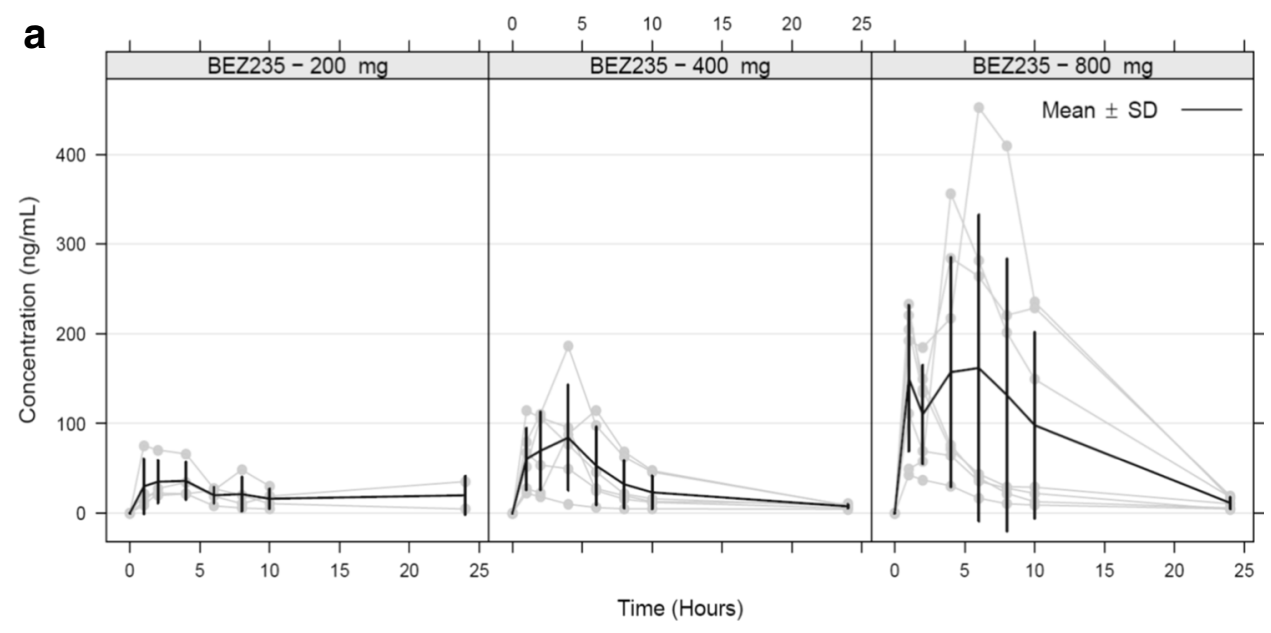

b

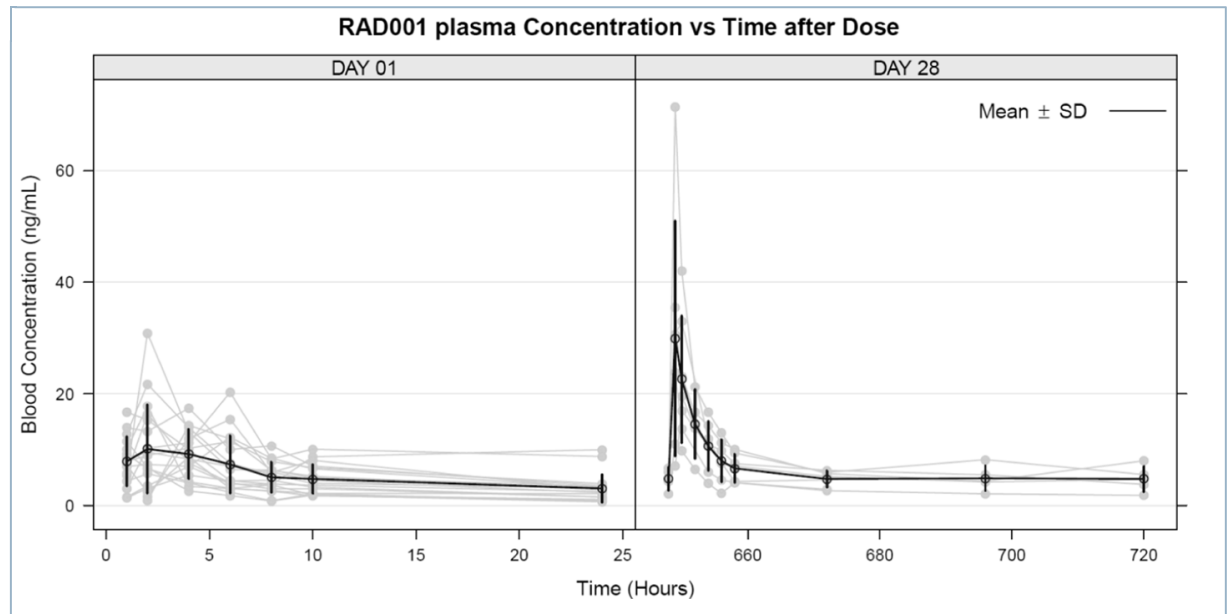

Table 3 Summary of BEZ235 and everolimus pharmacokinetic parameters on day 1 and day 28

\begin{tabular}{|c|c|c|c|c|c|c|c|c|}
\hline \multirow{3}{*}{$\begin{array}{l}\text { Pharmacokinetic } \\
\text { parameter } \\
(\text { Mean } \pm \mathrm{SE})\end{array}$} & \multicolumn{6}{|l|}{ BEZ235 Dose } & \multicolumn{2}{|c|}{ Everolimus Dose } \\
\hline & \multicolumn{2}{|l|}{$200 \mathrm{mg}$} & \multicolumn{2}{|l|}{$400 \mathrm{mg}$} & \multicolumn{2}{|l|}{$800 \mathrm{mg}$} & \multicolumn{2}{|l|}{$2.5 \mathrm{mg}$} \\
\hline & Day 1 & Day 28 & Day 1 & Day 28 & Day 1 & Day 28 & Day 1 & Day 28 \\
\hline $\begin{array}{l}\mathrm{AUC}_{0-24} \\
\quad(\mathrm{ng} * \mathrm{hr} / \mathrm{mL})\end{array}$ & $433.4 \pm 96$ & $1474 \pm 515.2$ & $741.3 \pm 171.2$ & $1458.1 \pm 1253.6$ & $2081.5 \pm 666.2$ & $7795.1 \pm 5608.7$ & $124.32 \pm 12.72$ & $218.8 \pm 33.26^{*}$ \\
\hline $\begin{array}{l}\mathrm{AUC}_{0-\infty} \\
\quad(\mathrm{ng} * \mathrm{hr} / \mathrm{mL})\end{array}$ & $468.5 \pm 118.2$ & $1487.9 \pm 690.9$ & $830.8 \pm 163.1$ & $2707.6 \pm 2343.3$ & $2167.3 \pm 674.9$ & $8877 \pm 6589.9$ & $191.15 \pm 33.72$ & $693.76 \pm 148.08$ \\
\hline $\mathrm{C}_{\max }(\mathrm{ng} / \mathrm{mL})$ & $45.2 \pm 11.4$ & $214.4 \pm 114.4$ & $101.8 \pm 22.4$ & $227.3 \pm 197.6$ & $243 \pm 52.7$ & $880.3 \pm 570.5$ & $14.08 \pm 1.5$ & $31.68 \pm 7.4$ \\
\hline $\begin{array}{l}\mathrm{C}_{\max } / \mathrm{Dose} \\
(\mathrm{ng} / \mathrm{mL} / \mathrm{mg})\end{array}$ & $0.2 \pm 0.1$ & $1.1 \pm 0.6$ & $0.3 \pm 0.1$ & $0.6 \pm 0.5$ & $0.3 \pm 0.1$ & $1.1 \pm 0.7$ & $5.63 \pm 0.6$ & $12.67 \pm 2.96$ \\
\hline $\mathrm{T}_{\max }(\mathrm{hr})$ & $3.8 \pm 1.6$ & $2.7 \pm 0.7$ & $2.5 \pm 0.9$ & $1.5 \pm 0.5$ & $2.6 \pm 0.8$ & $2 \pm 0$ & $4.3 \pm 1.2$ & $1.3 \pm 0.2^{*}$ \\
\hline $\begin{array}{l}\text { Terminal } \\
\quad \text { half-life (hr) }\end{array}$ & $3.2 \pm 1$ & $19.2 \pm 2.5$ & $8.6 \pm 1.5$ & $43.4 \pm 10.8$ & $5.9 \pm 0.7$ & $15 \pm 6.4$ & $15.69 \pm 2.33$ & $47.64 \pm 9.1^{*}$ \\
\hline \multirow[t]{2}{*}{$\begin{array}{l}\text { Apparent } \\
\text { clearance, } \\
\mathrm{CL} / \mathrm{F}(\mathrm{L} / \mathrm{hr})\end{array}$} & $629.6 \pm 278.1$ & $116.3 \pm 24.4$ & $644.3 \pm 192.9$ & $309.3 \pm 241.3$ & $773.9 \pm 262.1$ & $355.9 \pm 246.6$ & $24.76 \pm 2.91$ & $13.41 \pm 2.31^{*}$ \\
\hline & & & & & & & & ${ }^{*} P<0.05$ \\
\hline
\end{tabular}


Fig. 3 PK analysis for everolimus. a) Individual change in everolimus $\mathrm{AUC}_{0-24}$ and $\mathrm{CL} / \mathrm{F}$ from day 1 to day 28 . b) Simulated concentration-time profile of everolimus at $2.5 \mathrm{mg} /$ day using the reported population pharmacokinetic model (mean concentrations: black; $90 \%$ confidence interval: grey shaded area) and observed concentrations from the current study (mean: circles; $90 \%$ confidence interval: black line)
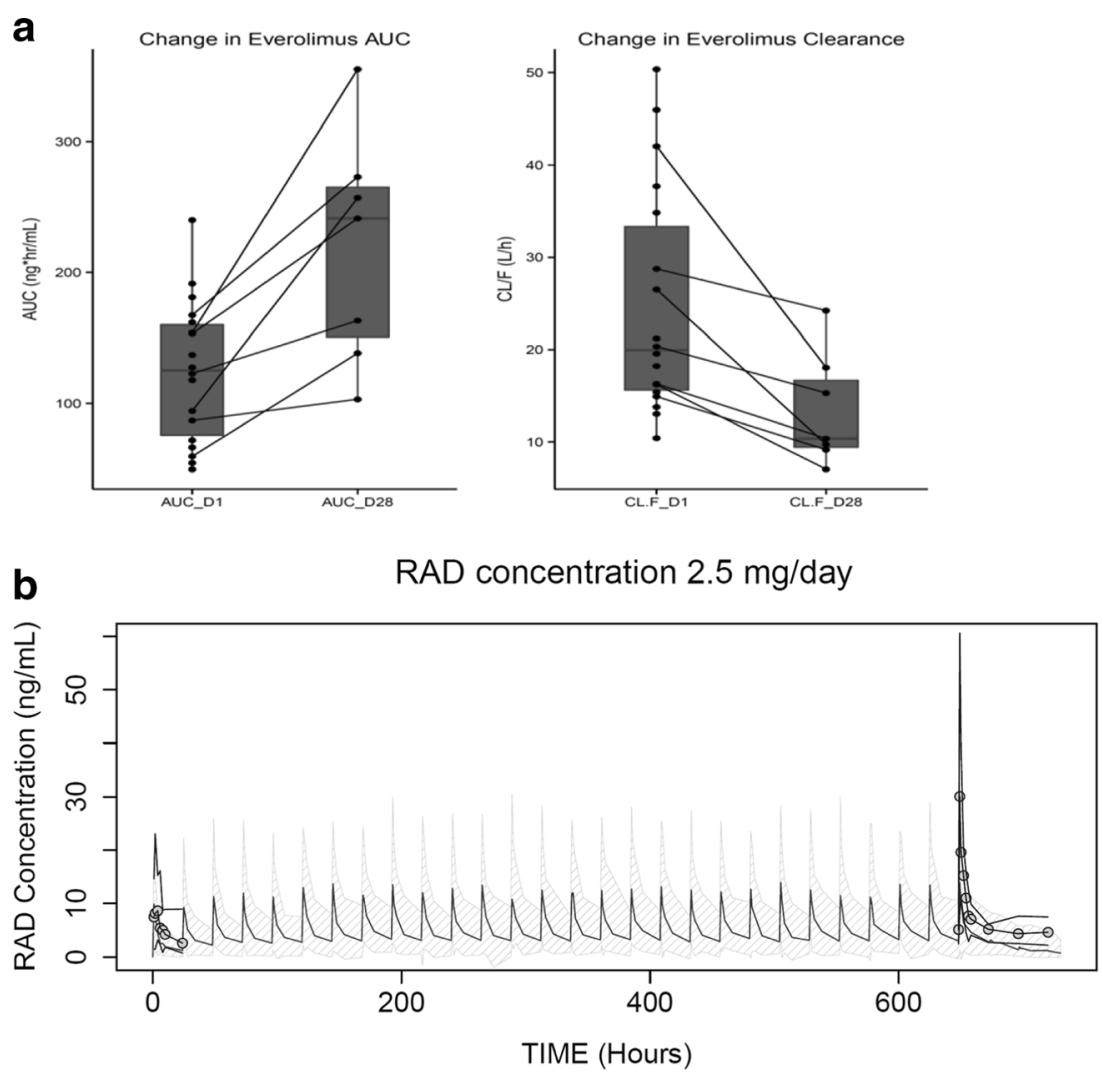

Additionally, we carried out population PK analysis of everolimus blood levels in patients enrolled in this study and compared the results to the reported population PK parameters of everolimus [23]. A two-compartment model of disposition fit the everolimus data well, and the final parameters including the inter-individual variability are reported in the supplementary Table 4 . We employed everolimus data from 18 subjects who completed day 1 dosing (123 blood levels) and from 7 subjects who also completed the day 28 cycle (60 blood levels). Based on the reported population PK parameters of everolimus including fixed effects (structural model parameters) and random effects (variance model parameters), everolimus concentrations were simulated for a once daily $2.5 \mathrm{mg}$ dose (Fig. 3b). There was no significant change in the everolimus exposure on day 1, as represented in Fig. 3, as most of the observed everolimus concentrations fell within a $90 \%$ prediction interval. However, almost all patients had everolimus concentrations outside the $90 \%$ prediction interval on day 28 , indicating a significant change in the everolimus PK on day 28.

\section{Discussion}

This is the first report of clinical PKs of BEZ235 combined with everolimus in patients with advanced solid tumors. Both single-dose and steady-state PK of BEZ235 were evaluated following 200, 400, and $800 \mathrm{mg}$ administration once daily for 28 days. From preclinical studies, it is known that BEZ235 has low oral bioavailability with highly variable systemic exposure due to poor aqueous solubility. Thus, we used a special delivery system (SDS) in the form of a sachet in an attempt to overcome poor solubility and to reduce the inter-individual variability in PK. Despite these efforts, our data suggest that the oral availability of BEZ235 remained low. Recently, Bendell et al. reported a similar highly variable PK of BEZ235 in a phase I study at doses 300-600 mg given twice daily using a similar SDS sachets [24].

The PK studies were focused primarily on assessing three important issues. Firstly, we explored the relationship between systemic exposure and the administered oral dose of BEZ235. Despite the inter-subject variability that is typically seen in advanced cancer patients, the $\mathrm{C}_{\max }$ and $\mathrm{AUC}_{0-24}$ increased in a linear (dose-proportional) manner following single dose administration. The power model also underscored this trend; although, with a slope factor of 1.21 for $\mathrm{C}_{\max }$ and 1.13 for $\mathrm{AUC}_{0-24}$, the increase may be supra-proportional. A limitation of the power model was that this phase I study was not primarily powered to detect any non-linearity in PK. Secondly, we evaluated the steady-state PK of BEZ235 to capture daily fluctuations in drug levels and the extent of drug accumulation upon multiple dosing. Steady-state PK, assessed on day 28 of the study could only be evaluated in a few subjects, which was difficult to analyze given dose proportionality and inter- 
subject variability. The average plasma concentration of BEZ235 ranged from $61-324 \mathrm{ng} / \mathrm{ml}$ at doses of 200 to $800 \mathrm{mg} /$ day. Accumulation was 2-3-fold higher than anticipated given the steady-state half-life of BEZ235, which ranged from 15-43 hrs. Exposure to a once daily dose of BEZ235 was comparable to twice-daily dosing reported by Bendell et al. [24]; $\mathrm{AUC}_{0-24}$ at $400 \mathrm{mg}$ once daily (741.3 $\mathrm{ng} * \mathrm{hr} / \mathrm{mL}$ ) was close to $200 \mathrm{mg}$ twice daily (752.9 $\mathrm{ng} * \mathrm{hr} / \mathrm{mL}$ ). Thirdly, we assessed if there was a PK interaction between BEZ235 and everolimus. The PK of everolimus has been well-characterized in healthy subjects and patients with advanced solid tumors with a linear PK observed at up to $10-\mathrm{mg} / \mathrm{day}$ doses. While rapidly absorbed after oral administration with a median $T_{\max }$ of $1-2$ hours, oral bioavailability of everolimus is low. This is believed to be due to extensive intestinal and first pass hepatic clearance mediated primarily by CYP3A4 metabolism and efflux by P-gp. Everolimus has a narrow therapeutic index and its FDA label recommends drug monitoring for everolimus when coadministered with CYP3A4 and/or P-gp inducers or inhibitors based on prior studies [16, 17]. In an earlier study employing a human liver microsomal system, we observed that BEZ235 is a time-dependent CYP3A4 inhibitor. Thus, we assessed the impact of BEZ235 on everolimus PK on day 1 and day 28 comparing our data to previous reports [23]. We employed both a non-compartmental and population-based PK analyses [25]. Results indicate that there was a significant change in everolimus PK due to BEZ235 co-administration. In all subjects, there was a significant decrease in everolimus clearance on day 28 from day 1 and clearance was lower than the reported clearance of everolimus monotherapy. Everolimus exposure when dosed along with BEZ235 was 1.7-fold higher and the resulting mean everolimus exposure at $2.5 \mathrm{mg} /$ day was approximately equivalent to everolimus $5-\mathrm{mg}$ /day monotherapy. Using a population-based PK model, we showed that the observed everolimus concentrations on day 1 were consistent with the previously reported everolimus PK; however, there was a significant increase in exposure on day 28. Time-dependent inhibition of CYP3A4 by BEZ235 could potentially rationalize this increase in everolimus exposure.

Most adverse events observed were consistent with the reported profile of mTOR inhibitors including fatigue, mucositis, diarrhea, nausea, and myelosuppression, or PI3K inhibitors including elevated liver enzymes [4, 5, 24]. Potentially, the low oral bioavailability of BEZ235 resulted in high GI concentrations contributing to the GI-specific toxicities reported. However, unanticipated toxicities were also observed, including the development of TLS. It is unclear whether this was directly related to the study medication, but may implicate increased response in this patient. Unfortunately, the patient who developed TLS on treatment succumbed to complications of TLS. It should be cautionary to consider allopurinol TLS prophylaxis in patients with aggressive, highly proliferative tumors and a high volume of disease who will receive mTOR/PI3K inhibitors. Tapering of steroids was required in our study and we observed that patients with GBM often developed rapid deterioration that prohibited patient continuation on study. Therefore, patients requiring steroids may not be ideal candidates for this treatment.

Although this study was not designed to capture efficacy, and preclinical studies demonstrated the synergy of combining an mTOR inhibitor and a dual mTOR/PI3K inhibitor (BEZ235), we did not observe any RECIST-defined responses in this phase 1 trial. There was one patient who had SD and one who had a brief clinical response in cohort 3 . However, due to subjective and objective unacceptable toxicity, patients were unable to complete two cycles of treatment at the escalated dose of BEZ235. Moreover, pharmacodynamics (PD) analyses using patient-derived mononuclear cells from day 1 (pre-treatment) and 28 (post-treatment) in six patients showed a trend towards decreased phosphorylation of $4 \mathrm{E}-\mathrm{BP} 1$, a downstream substrate of mTOR (data not shown). However, the inter-patient variability and the low number of patients per treatment cycle preclude any conclusive statement regarding PD. Altogether, the poor bioavailability of BEZ235 combined with the reported toxicities prevented dose escalation to where efficacy could potentially be achieved. Thus, to avoid these toxicities and achieve a dose likely to be impact the PI3K/ mTOR pathway, a formulation that markedly enhances the oral bioavailability or delivery of the drug via a non-oral route must be considered.

Importantly, it should be noted that development of dactolisib has been halted. Other clinical studies in several tumors including a phase I trial of BEZ235 alone in pancreatic neuroendocrine tumors [26] and a combination study with mTOR inhibition in bladder cancer [27] also showed that BEZ235 was poorly tolerated as the MTD was $300 \mathrm{mg}$ in the phase I study [24]. These studies did demonstrate limited clinical efficacy with several patients with stable disease but given the poor tolerability, these trials did not advance.

Our studies provide the first detailed report on the PK of BEZ235 in combination with everolimus and suggest that the systemic exposure of BEZ235 likely exhibits a linear/doseproportional pattern in the range of $200-800 \mathrm{mg}$. At steady state, drug levels are $\sim 3$-fold higher than following single dose administration. The compound is likely to cause changes in the PK of drugs where CYP3A4 plays a prominent role, as was observed with everolimus. Most likely this interaction occurs in the gastrointestinal (GI) tract since everolimus is known to undergo extensive pre-systemic clearance and the intestinal concentrations of BEZ235 are likely to be higher given its low oral bioavailability. Thus, this interaction may not make a major impact on drugs that are not metabolized in the GI tract. The results of our studies strongly underscore the critical need for consideration of biopharmaceutical properties in designing investigational agents targeting mTOR/PI3K 
signaling and drug delivery approaches, in order to achieve therapeutically relevant systemic drug exposure.

\section{Compliance with Ethical Standards}

Funding The investigational agent, dactolisib (BEZ 235) used in this study, and funding for the pharmacokinetic analysis of patient samples was provided by Novartis Oncology (East Hanover, NJ, USA). Trisha Wise-Draper is supported by the clinical scientist training program at the University of Cincinnati (UC). Hala Elnakat Thomas is supported by a faculty pilot project grant by the Department of Internal Medicine at UC and a just-in-time award by the UC Cancer Center. We would also like to thank the Lcs Foundation for their support.

Conflict of Interest Nagal Abdel Karim has received payment for lectures on everolimus for FDA-approved indications. Sara Kozma was an employee at the Friedrich Miescher Institute for Biomedical Research in Basel, Switzerland, which is affiliated with the Novartis Institute for Biomedical Research, from 1986 to 2003. George Thomas was employed as a scientific consultant by Novartis Oncology from 2000-2010. Olivier Rixe has received grants from Novartis through the University of Cincinnati to support the clinical trial and correlative studies. All other authors declare no conflicts of interest.

Open Access This article is distributed under the terms of the Creative Commons Attribution-NonCommercial 4.0 International License (http:// creativecommons.org/licenses/by-nc/4.0/), which permits any noncommercial use, distribution, and reproduction in any medium, provided you give appropriate credit to the original author(s) and the source, provide a link to the Creative Commons license, and indicate if changes were made.

\section{References}

1. Dancey JE, Chen HX. Strategies for optimizing combinations of molecularly targeted anticancer agents. Nat Rev Drug Discov. 2006;5(8):649-59.

2. Wymann MP, Zvelebil M, Laffargue M. Phosphoinositide 3-kinase signalling-which way to target? Trends Pharmacol Sci. 2003;24(7): 366-76.

3. Motzer RJ et al. Efficacy of everolimus in advanced renal cell carcinoma: a double-blind, randomised, placebo-controlled phase III trial. Lancet. 2008;372(9637):449-56.

4. Yao JC et al. Everolimus for advanced pancreatic neuroendocrine tumors. N Engl J Med. 2011;364(6):514-23.

5. Baselga $\mathrm{J}$ et al. Everolimus in postmenopausal hormone-receptorpositive advanced breast cancer. N Engl J Med. 2012;366(6):520-9.

6. Carayol $\mathrm{N}$ et al. Critical roles for $\mathrm{mTORC2}$ - and rapamycininsensitive mTORC1-complexes in growth and survival of BCRABL-expressing leukemic cells. Proc Natl Acad Sci U S A. 2010;107(28):12469-74.

7. Sabatini DM. mTOR and cancer: insights into a complex relationship. Nat Rev Cancer. 2006;6(9):729-34.

8. Maira SM et al. Identification and characterization of NVPBEZ235, a new orally available dual phosphatidylinositol 3-kinase/mammalian target of rapamycin inhibitor with potent in vivo antitumor activity. Mol Cancer Ther. 2008;7(7):1851-63.
9. Awasthi $\mathrm{N}$ et al. The efficacy of a novel, dual PI3K/mTOR inhibitor NVP-BEZ235 to enhance chemotherapy and antiangiogenic response in pancreatic cancer. J Cell Biochem. 2012;113(3):784-91.

10. Brachmann SM et al. Specific apoptosis induction by the dual PI3K/mTor inhibitor NVP-BEZ235 in HER2 amplified and PIK3CA mutant breast cancer cells. Proc Natl Acad Sci U S A. 2009;106(52):22299-304.

11. Cao P et al. Activity of a novel, dual PI3-kinase/mTor inhibitor NVP-BEZ235 against primary human pancreatic cancers grown as orthotopic xenografts. Br J Cancer. 2009;100(8):1267-76.

12. Engelman JA et al. Effective use of PI3K and MEK inhibitors to treat mutant Kras G12D and PIK3CA H1047R murine lung cancers. Nat Med. 2008;14(12):1351-6.

13. Thomas HE et al. mTOR inhibitors synergize on regression, reversal of gene expression, and autophagy in hepatocellular carcinoma. Sci Transl Med. 2012;4(139):139ra84.

14. Picard $\mathrm{N}$ et al. CYP3A5 genotype does not influence everolimus in vitro metabolism and clinical pharmacokinetics in renal transplant recipients. Transplantation. 2011;91(6):652-6.

15. Crowe A et al. Absorption and intestinal metabolism of SDZ-RAD and rapamycin in rats. Drug Metab Dispos. 1999;27(5):627-32.

16. Kovarik JM et al. Pharmacokinetic interaction between verapamil and everolimus in healthy subjects. Br J Clin Pharmacol. 2005;60(4):434-7.

17. Kovarik JM, Beyer D, Schmouder RL. Everolimus drug interactions: application of a classification system for clinical decision making. Biopharm Drug Dispos. 2006;27(9):421-6.

18. Eisenhauer EA et al. New response evaluation criteria in solid tumours: revised RECIST guideline (version 1.1). Eur J Cancer. 2009;45(2):228-47.

19. Oken MM et al. Toxicity and response criteria of the Eastern Cooperative Oncology Group. Am J Clin Oncol. 1982;5(6):64955.

20. Lin $\mathrm{F}$ et al. Determination of NVP-BEZ235, a dual PI3K and mTOR inhibitor, in human and mouse plasma and in mouse tissue homogenates by reversed-phase high-performance liquid chromatography with fluorescence detection. J Chromatogr B Analyt Technol Biomed Life Sci. 2012;901:9-17.

21. Fouladi $\mathrm{M}$ et al. Phase I study of everolimus in pediatric patients with refractory solid tumors. J Clin Oncol. 2007;25(30):4806-12.

22. Kirchner GI, Meier-Wiedenbach I, Manns MP. Clinical pharmacokinetics of everolimus. Clin Pharmacokinet. 2004;43(2):83-95.

23. US-FDA. Center for Drug Evaluation and Research clinical pharmacology and biopharmaceutics review for everolimus [online]. 2014 DEC 01]; Available from: http://www.accessdata.fda.gov/ drugsatfda docs/nda/2009/022334s000 ClinPharmR.pdf.

24. Bendell JC, et al. A phase 1 study of the sachet formulation of the oral dual PI3K/mTOR inhibitor BEZ235 given twice daily (BID) in patients with advanced solid tumors. Investig New Drugs. 2015.

25. US-FDA. Drug interaction studies - study design, data analysis, implications for dosing, and labeling recommendations (draft guidance). Maryland: US Food and Drug Administration; 2012.

26. Fazio N et al. A Phase II Study of BEZ235 in Patients with Everolimus-resistant, Advanced Pancreatic Neuroendocrine Tumours. Anticancer Res. 2016;36(2):713-9.

27. Seront E et al. Phase II study of dual phosphoinositol-3-kinase (PI3K) and mammalian target of rapamycin (mTOR) inhibitor BEZ235 in patients with locally advanced or metastatic transitional cell carcinoma. BJU Int. 2016;118(3):408-15. 